Methods we reviewed retrospectively all the data of 184 patients receiving complete cytoreductive surgery, whether as primary or interval debulking between January 2005 and ocotber 2019 at Hôtel-Dieu de France University Hospital.

Results Median age at surgery was 56 years. 41,8\% benefited from a primary cytoreductive surgery while $42,9 \%$ of patients received their surgery after a neoadjuvant chemotherapy. $74 \%$ of patients were in stage III. High-grade serous epithelial ovarian cancer was the most encountered histology (69\%). Bowel resection and upper abdominal surgery was needed in $46 \%$ and $39,1 \%$ of cases, respectively. Survival rate was $66 \%$ (122 out of 184 patients). No recurrence was noted in $53,8 \%$ of cases and $74,7 \%$ of recurrences occurred after 12 months. According to cox regression test, better survival was significantly correlated to younger age $(<50$ years), negative lymph node status, lymph node ratio $(<$ 0,18 ), early stage, primary surgery, no bowel resection, no more than one positive lymph node $(p=0.006, p=0.000$, $\mathrm{p}=0.000, \mathrm{p}=0.000, \mathrm{p}=0.001, \mathrm{p}=0.000, \mathrm{p}=0.000$, respectively). Early recurrence was correlated to advanced stage $(p=0.000)$, positive lymph node status $(\mathrm{p}=0.002)$, bowel resection $(p=0.046)$, interval surgery $(p=0.025)$. In the multivariate analysis, survival was only correlated to lymph node status, lymph node ratio, stage, absence of bowel resection and number of positive lymph nodes.

Conclusion Negative lymph node status, LNR $<0.18$, early stage, absence of bowel resection and the presence of only one positive $\mathrm{LN}$ predict a better survival.

\section{IGCS20 1428}

\section{IMPACT OF A LAPAROSCOPIC TRIAGE PROGRAM FOR ADVANCED OVARIAN CANCER ON SURGICAL OUTCOMES, DISEASE-FREE SURVIVAL, AND OVERALL SURVIVAL}

${ }^{1} \mathrm{I}$ Mulder*, ${ }^{1} \mathrm{~N}$ Fleming, ${ }^{1} \mathrm{C}$ Sun, ${ }^{1} \mathrm{~B}$ Fellman, ${ }^{1} \mathrm{~L}$ Ulin, ${ }^{1} \mathrm{M}$ Ozer, ${ }^{2} \mathrm{R}$ Coleman, ${ }^{1} \mathrm{P}$ Ramirez, ${ }^{1} \mathrm{~K}$ Rangel, ${ }^{1} \mathrm{P}$ Soliman, ${ }^{3} \mathrm{~A}$ Nick, ${ }^{1} \mathrm{~K}$ Lu, ${ }^{1} \mathrm{~A}$ Sood, ${ }^{1} \mathrm{~S}$ Westin. ${ }^{1}$ University of Texas MD Anderson Cancer Center, USA; ${ }^{2}$ US Oncology Network, USA; ${ }^{3}$ Tennessee Oncology, USA

\subsection{6/ijgc-2020-IGCS.344}

Introduction This study evaluates whether implementing a laparoscopic triage algorithm (LSC) to grade initial disease burden impacts surgical outcomes, disease-free survival (DFS), and overall survival (OS) in advanced ovarian cancer (OC).

Methods In 2013, LSC was implemented for advanced high-grade serous OC. LSC scores volume and distribution of intra-abdominal disease in order to disposition patients to either primary cytoreductive surgery (PDS) or neoadjuvant chemotherapy (NACT) followed by interval cytoreduction. Outcomes for patients offered management with LSC (post-LSC) were compared to a cohort from 2010-2012 who would have qualified for laparoscopy (pre-LSC). Summary statistics were used to describe surgical outcomes, and DFS and OS were estimated using the Kaplan-Meier method.

Results Between 2013-2016, 201 OC patients were offered LSC; 182 underwent laparoscopy. We identified 161 preLSC control patients for comparison. There were no differences in clinicodemographic features between both cohorts.
Prior to implementing LSC, 64 (40\%) patients underwent PDS compared to $88(44 \%)$ post-LSC $(\mathrm{p}=0.42)$. Complete cytoreduction (R0) was achieved more frequently in the post-LSC cohort (81 vs $51 \%, \mathrm{p}<0.001)$. There were no differences in median DFS or OS between pre- and post-LSC cohorts (DFS 17 vs 16 months, $p=0.76$; OS 45 vs 48 months, $\mathrm{p}=0.38$ ). However, within the PDS group, a significantly greater median OS was observed in post-LSC compared to pre-LSC cohort (not reached vs 51 months, $\mathrm{p}<0.013)$.

Conclusion Our data suggest that LSC allows for a greater R0 resection rate and, for patients triaged to PDS, is associated with improved median OS.

\section{IGCS20_1429}

\section{SURGICAL MORBIDITY OF THE RETROPERITONEAL STAGING IN PATIENTS UNDERGOING SURGERY FOR EARLY STAGE EPITHELIAL OVARIAN CANCER}

M Dri*, A Lembo, M Longo, N Oltolina, M Riva, V Artuso, F Ghezzi, J Casarin. Obstetrics and Gynecology Dpt. University of Insubria, Italy

\subsection{6/ijgc-2020-IGCS.345}

Introduction Surgery is the cornerstone of the apparent early stage ovarian cancer (aEOC) treatment. For the purpose of this study we evaluated perioperative outcomes and 30-days surgical morbidity of the retroperitoneal staging in patients undergoing surgery for aEOC.

Methods This is a retrospective single-center observational study conducted at Del Ponte Hospital of Varese (Italy) between January 2000 and December 2019. We included consecutive patients who underwent surgery for aEOC over the study period. Women who had a fertility-sparing approach were excluded. The cases were stratified into two groups: lymph node dissection performed (LND) and not-performed

\begin{tabular}{|c|c|c|c|}
\hline \multicolumn{4}{|c|}{ Baseline population characteristics } \\
\hline & $\begin{array}{l}\text { RETROPERITONEAL STAGING } \\
n=71(65.45 \%)\end{array}$ & $\begin{array}{l}\text { NO RETROPERITONEAL STAGING } \\
n=38(34.86 \%)\end{array}$ & $p$-value \\
\hline Age & $54.9(49-63)$ & $55.5(45-68)$ & 0.81 \\
\hline Menopause & $48(67.6 \%)$ & $22(57.9 \%)$ & 0.31 \\
\hline Parity & $1(0-3)$ & $2(0-5)$ & 0.22 \\
\hline Previous open surgery & $23(32.4 \%)$ & $16(42.1 \%)$ & 0.31 \\
\hline Previous laparoscopy & $25(35.2 \%)$ & $5(13.2 \%)$ & 0.01 \\
\hline \multicolumn{4}{|c|}{ Surgical outcomes } \\
\hline & $\begin{array}{l}\text { RETROPERITONEAL STAGING } \\
n=71(65.45 \%)\end{array}$ & $\begin{array}{l}\text { NO RETROPERITONEAL STAGING } \\
\mathrm{n}=38(34.86 \%)\end{array}$ & $p$-value \\
\hline Operative time (min) & $325(240-390)$ & $135(70-200.5)$ & $<0.001$ \\
\hline Blood loss (ml) & $300(137.5-500)$ & $100(50-325)$ & 0.72 \\
\hline Intra-operative transfusion & $7(9.9 \%)$ & $1(2.6 \%)$ & 0.18 \\
\hline In-hospital transfusion & $5(7.7 \%)^{*}$ & $1(2.9 \%)^{* *}$ & 0.33 \\
\hline Intra-operative complications & $4(5.6 \%)$ & $1(2.6 \%)$ & 0.48 \\
\hline In-hospital complications & $6(8.8 \%)^{* *}$ & $3(7.9 \%)$ & 0.90 \\
\hline Post-discharge complications & $12(16.9 \%)$ & $3(7.9 \%)$ & 0.19 \\
\hline Non-surgical complications & $3(4.2 \%)$ & $4(10.5 \%)$ & 0.20 \\
\hline
\end{tabular}

